\title{
Adoption of Drip Irrigation System by the Farmers in Bikaner District of Rajasthan
}

\author{
H. L. Verma ${ }^{1 *}$ and S. K. Sharma ${ }^{2}$ \\ ${ }^{1}$ Subject Matter Specialist (Agril. Ext.) Krishi Vigyan Kendra Nyoma (Leh), SKUAST- \\ Kashmir, J\&K (India) 194404. \\ ${ }^{2}$ Director Extension Education, Swami Keshwanand Rajasthan Agricultural University \\ Bikaner, Rajasthan (India) 334006 \\ *Corresponding author
}

\section{A B S T R A C T}

\begin{tabular}{|l|}
\hline Keyw or d s \\
$\begin{array}{l}\text { Adoption, Drip } \\
\text { irrigation system }\end{array}$ \\
\hline Article Info \\
\hline $\begin{array}{l}\text { Accepted: } \\
\text { 15 February } 2020 \\
\text { Available Online: } \\
10 \text { March } 2020\end{array}$ \\
\hline
\end{tabular}

Water is a well known basic and the most important input for agricultural production. A major quantity of water is utilized for irrigation in agriculture. In traditional surface irrigation method the losses in water conveyance and application are large. These losses can be considerably reduced by farmers by adopting drip irrigation technology. Proper economization of water would be advantageous to the farmers as well as it would be helpful in bringing more land under cultivation. In order to use such a precious natural resource economically, drip irrigation would be a possible solution which minimizes the losses of water and fertilizer as well as increase the yield of crops resulting the more profit and quality of product. The present study was conducted in four panchayat samities (out of six) in Bikaner district of Rajasthan. From the selected four panchayat samities, a total of 234 respondent farmers having drip irrigation system were selected randomly for the study purpose. The data were collected by personal interview method with the help of interview schedule. The data so collected were classified, tabulated and statistically analyzed. The findings of the study revealed that majority of ( 62.82 per cent) the respondents were found medium adopters of drip irrigation system followed by 20.94 per cent respondents were low adopters and 16.24 per cent respondents were high adopters of drip irrigation system. Further, it was concluded that the parameter of 'Spacing between two emitters and laterals' was widely adopted by the farmers. Whereas, the farmers least adopted the parameter like the whole 'area under drip irrigation system' could not covered due to the high initial investment and lack of resources.

\section{Introduction}

The agricultural production plays a very crucial role in the national economy. The increase in human population together with rapid industrial and urban development resulted in a sharp rise in the demand for agricultural products. Intensive agriculture and our growing population are depleting the already scare resource, the water. This is 
challenging situation and the need of hour is to conserve water and ensure its efficient use. Our aim today is to increase agricultural production per drop of water.

Increasing competition of water with the other water users in the future would limit the water availability for expanding irrigated area. Recognized the fast decline of irrigation water potential and increasing demand for water from different sectors there has been a demand of management strategies and programme to save water and increase the existing water use efficiency in Indian Agriculture.

In this changing agricultural scenario and a shift towards precision farming, drip irrigation happens to be the technology capable of providing more efficient utilization of water.

Drip irrigation also known as trickle irrigation or micro irrigation is an irrigation method which minimizes the use of water and fertilizer by allowing water to drip slowly to the roots of plants, either on to the soil surface or directly on to the root zone, through a network of valves, pipes, tubing, and emitters. Drip irrigation is most suitable for row crops (vegetables, soft fruit), tree and vine crops where one or more emitters can be provided for each plant. Drip irrigation is adaptable to any farmable slope and most soils (FAO, 1988).

The modern technology of drip irrigation was invented in Israel by Simcha Blass and his son Yeshayahu in 1959 when Blass partnered (1964) with Kibbutz Hatzerim to create an irrigation company called Netafim (Postel et al., 2001).

The drip irrigation system is especially, suitable for saline and alkaline soil and water use efficiency under drip irrigation system is
80 to 90 per cent. Bahuguna (1996) stated that by drip irrigation system 95 per cent of the irrigation water can be used efficiently and by this method 30 to 50 per cent production may be increased.

Drip irrigation system saves $40-70$ per cent water as compared to surface irrigation method and reduces labour cost, protects the plants from diseases by minimizing humidity in atmosphere. Soluble fertilizer can also be applied with irrigation water. Thus, drip irrigation has become a means of hi-tech agriculture, Horticulture and Precision farming.

Rajasthan is the largest state in India having about 11 per cent area of the country. However water availability is only 1 per cent of the country and average rain fall is 575 $\mathrm{mm}$. The major source of water in the state is well and tube wells. Irrigation scenario of Rajasthan is characterized by erratic or scanty rainfall, dwindling ground water resources, increasing alternative demand of municipal and industrial sector that means less water available for agriculture. Under such condition management of irrigation requires adequate attention for efficient utilization of every drop of water.

Although the drip irrigation system seems to be the most effective system in Rajasthan conditions. However, the adoption of this system is not as desired. Seeing is believing and learning by doing is an important principle of extension which leads to adoption of innovations. The adoption of drip irrigation is not an exception to this phenomenon. But the question is to which extent the farmers have adopted this system in their fields and the benefits derived by adopting drip irrigation system by the farmers would certainly change the mind set of neighbouring farmers to move towards acceptance of this technology. Keeping all these views in mind 
the present investigation entitled "Adoption of drip irrigation system by the farmers in Bikaner district of Rajasthan" was under taken.

\section{Materials and Methods}

the present study was conducted in Bikaner district of Rajasthan. Out of six, four panchayat samities were selected purposely on the basis of highest area and large number of beneficiary farmers of drip irrigation system. From the selected four panchayat samities 25 per cent farmers having drip irrigation system were selected randomly. Hence, total sample of 234 respondent farmers were selected for the study purpose.

The data were collected by personal interview method with the help of interview schedule. The data so collected were tabulated and analyzed. Inferences were drawn after subjecting the data to statistical analysis.

\section{Results and Discussion}

The extent of adoption was worked out by means of adoption index developed by the investigator and the scoring was done accordingly. Based on the scores obtained by the respondents, mean score and standard deviation were computed for the purpose of classifying the adoption level in to three classes namely low, medium, and high. In this way the respondents were classified in to three groups.

Statistical data regarding the extent of adoption of drip irrigation system by the farmers have been presented in Table 1 .

The data revealed that 62.82 per cent respondents were found to be medium adopters and 20.94 per cent respondents were low adopters, while 16.24 per cent respondents were categorized as high adopters of drip irrigation system.
It may be concluded that majority of the respondents were medium adopters of drip irrigation system as per recommendations. Only a small percentage of respondents could be categorized as low and high adopters of drip irrigation system.

It also seems that still there was gap between what was recommended and adopted by the respondents. While interviewing with the respondents, it was reported that half of them were facing the problem of non-availability of technical guidance.

Further, the extent of adoption about different parameters of drip irrigation system was analyzed separately. The relative importance of extent of adoption of all the six parameters of drip irrigation system was highlighted by ranking them in descending order on the basis of their percentage of adoption and data have been presented in Table 2 .

The data revealed that the adoption of different parameters i.e. 'spacing between two emitters and laterals' was 88.03 per cent by the respondents and assigned rank first. The second rank was accorded to the 'number of emitters per plant' as it was adopted the extent of 73.40 per cent. Likewise 'operation \& maintenance' (70.30 per cent), 'fertigation \& chemigation' (66.33 per cent), 'irrigation schedule' (62.82 per cent) and 'area under drip irrigation system' (26.59 per cent) were assigned ranked III, IV, V, and VI, respectively.

Further the data presented in Table 2 also indicated that overall extent of adoption of drip irrigation system by the farmers was 64.58 per cent.

About the extent of adoption of individual parameters of drip irrigation system, it was noted that extent of adoption in 'spacing between two emitters and laterals' was widely adopted parameter. The results seemed to be 
quite natural because of the fact that drip irrigation kit can easily fix and adjust laterals pipes and micro tubes of the kit in the field. The second highest adoption was found in the parameter like 'number of emitters per plant'. This might be due to the fact that drip irrigation system was widely used in vegetable crops and fruit plants, and with the adoption of these parameters properly lead to the equal distribution of water in the crops and plants.

'Operation and maintenance' parameter was adopted by more than $2 / 3^{\text {rd }}$ of the respondents. This might be due to the reasons that there was lack of technical guidance about it, after installation of drip irrigation system, the installation agencies were not providing the proper technical services related to the operation and maintenance aspect of drip irrigation system in the field. The farmers could not cover all the cultivated area by drip irrigation system because of high initial investment. Therefore, the farmers could not adopt it in whole of the area. The findings of the study are in accordance with the findings of Patel et al., (2012), Andhukar et al., (2013) and Bhuriya et al., (2015) who reported that majority of the respondents had medium level of adoption about drip irrigation system.

Table.1 Distribution of respondents according to extent of adoption of drip irrigation system

\begin{tabular}{|c|l|c|c|}
\hline \multicolumn{2}{|c}{ Adopter categories } & Frequency & Percentage \\
\hline S. No. & \multicolumn{1}{|c|}{ Ad4 } & 20.94 \\
\hline $\mathbf{1}$ & Low adopters (score below 53) & 49 & 62.82 \\
\hline $\mathbf{2}$ & Medium adopters (score from 53 to 83) & 147 & 16.24 \\
\hline $\mathbf{3}$ & High adopters (score above 83) & 38 & 100.00 \\
\hline & Total & 234 & 1000 \\
\hline
\end{tabular}

Mean $68.00 \quad$ S.D. 15.00

Table.2 Extent of adoption of different parameters of drip irrigation system by the farmers

\begin{tabular}{|c|l|c|c|}
\hline S. No. & \multicolumn{1}{|c}{ Parameters } & $\begin{array}{c}\text { Extent of } \\
\text { adoption (\%) }\end{array}$ & Rank \\
\hline $\mathbf{1}$ & Spacing between two emitters and laterals & 88.03 & I \\
\hline $\mathbf{2}$ & Number of emitters per plant & 73.40 & II \\
\hline $\mathbf{3}$ & Operation and maintenance & 70.30 & III \\
\hline $\mathbf{4}$ & Fertigation and chemigation & 66.33 & IV \\
\hline $\mathbf{5}$ & Irrigation schedule & 62.82 & V \\
\hline $\mathbf{6}$ & Area under drip irrigation system & 26.59 & VI \\
\hline & Overall adoption & 64.58 & \\
\hline
\end{tabular}

From the above findings it can be concluded that majority of the farmers were medium adopters of drip irrigation system. Therefore, In order to convert medium adopters into high adopters, extension agencies should give more emphasis on the methodologies for transfer of technologies in an acceptable manner. In respect of adoption parameters of the drip irrigation system i.e. 'Spacing between two emitters \& laterals' was widely adopted by the farmers because the drip irrigation kit can easily fix and adjust laterals pipes and micro tubes of the kit in the field. Whereas, the farmers could not cover the 
whole 'area under drip irrigation system' due to the high initial investment and lack of resources. Hence, it is advised that the subsidy provision be enhanced for motivating the farmers and simultaneously the farmers, may be provided bank loan in a simplified manner for this purpose.

\section{References}

Aundhkar, R.S., Deshmukh, A.N., Tale, S.G. and Shinde, P.P. 2013. Adoption of drip irrigation technologies by the orange growers. Agriculture Update. 8 (4): 620-622.

Bahuguna, S.L. 1996. Jal Ki barbadi rokna jaruri. Krishi Chayanika. 17 (1):27-32.

Bhuriya, R., Choudhary S., and Swarnakar, V.K. 2015. Study of Adoption
Behaviour of Drip Irrigation System on Chilli Crop in Barwani District of M.P. India. IOSR Journal of Agriculture and Veterinary Science. 8 (12): 12-14.

FAO, 1988. Irrigation Water Management: Irrigation Methods. Training manual. 5: 52-56.

Patel, Y., Choudhary, S. and Swarnakar, V.K. 2012. Study on adoption behavior of farmers towards drip irrigation system (DIS) in Khargone block of Khargone district (M.P.), India. International Journal of Innovative Research \& Development. 1 (11): 319-325.

Postel, S., Polak P., Gonzales F. and Keller J. 2001. Drip Irrigation for Small Farmers: A New Initiative to Alleviate Hunger and Poverty. 26: 1.

\section{How to cite this article:}

Verma, H. L. and Sharma, S. K. 2020. Adoption of Drip Irrigation System by the Farmers in Bikaner District of Rajasthan. Int.J.Curr.Microbiol.App.Sci. 9(03): 2331-2335. doi: https://doi.org/10.20546/ijcmas.2020.903.265 